\title{
Wrong Signals
}

\section{Dear Reader,}

After many years of discussing the best approach to promoting electric-vehicle technology in the larger framework of Germany's energy-sector transition, the German government has finally agreed to introduce subsidies on the purchase of electric vehicles. In doing so, Germany is following in the footsteps of other European countries in which efforts to stimulate the market have shown considerable success.

As of May 2016, purchasers of new battery electric vehicles in Germany will receive a government rebate of 4000 euros and purchasers of new plug-in hybrid electric vehicle will receive a rebate of 3000 euros. The program is limited to a total subsidy volume of 1.2 billion euros, with the automobile manufacturers contributing $50 \%$ of the total. Between 2017 and 2020, an additional 300 million euros is to be allocated to an expansion of the country's electric vehicle charging infrastructure, with 200 million euros being earmarked for fast charging stations and 100 million euros for conventional charging stations.

Regrettably, a closer look at the allocation figures reveals a story of misplaced priorities - with respect to engine types, charging station types and the relative importance of vehicles versus infrastructure. For instance, it is questionable whether plug-in hybrid vehicles, given their current form and use, deserve to be subsidised at all. Their inclusion in the program means that the government is effectively subsidising large SUVs that make use of the hybrid technology and inflated fuel-efficiency claims (déjà vu) to establish compliance with corporate average fuel economy standards (NEDC and WLTP) - and that at a rate that is only 1000 euros less than that for battery electric vehicles. Indeed, testing of the editorial office confirms that the electricpowered driving range of $50 \mathrm{~km}$ claimed by the OEM for their plug-in hybrid cars are inflated. What they really offer is around $35 \mathrm{~km}$ in ideal conditions and with the help of sophisticated fuel-saving driving strategies. Fuel efficiency claims on the order of $2.1 \mathrm{l} / 100 \mathrm{~km}$ are simply unrealistic? Again, the industry has sadly missed an opportunity to win over customers with straightforward claims based on real-world driving conditions. And the loss of trust that people will experience when their expectations are again disappointed in the case of electric vehicles may be insurmountable.

Battery electric vehicles, i.e. real electric vehicles, offer real-world driving ranges of $150 \mathrm{~km}$ - and counting. However, this is another area in which lawmakers need to earn credibility and trust. A denser network of charging stations would indeed significantly temper the debate on driving ranges. Here, too, the German government has sent the wrong signals. An investment of 200 million euros in the more expensive fast charging stations is far too little.

There are more effective approaches to promoting electric-vehicle technology, for instance, by expanding the country's charging infrastructure. This would reveal the absurdity of waiting for perfection, record driving ranges and super batteries.

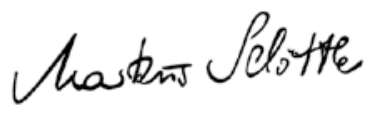

\section{Markus Schöttle}

Deputy Editor in Chief

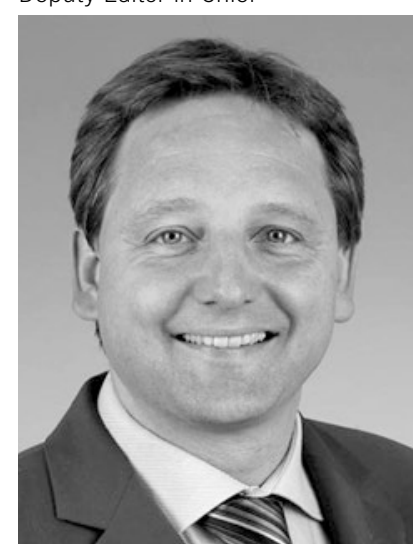

